\title{
Comparative effectiveness of robotic and open radical prostatectomy
}

\author{
Rodrigo Rodrigues Pessoa ${ }^{1}$, Paul Maroni ${ }^{1}$, Janet Kukreja ${ }^{1}$, Simon P. Kim ${ }^{1,2}$ \\ ${ }^{1}$ Division of Urology, University of Colorado Anschutz Medical Center, Aurora, Colorado, USA; ${ }^{2}$ Cancer Outcomes and Public Policy Effectiveness \\ Research (COPPER), Yale University, New Haven, Connecticut \\ Contributions: (I) Conception and design: SP Kim; (II) Administrative support: P Maroni; (III) Provision of study material or patients: RR Pessoa; \\ (IV) Collection and assembly of data: RR Pessoa; (V) Data analysis and interpretation: RR Pessoa, SP Kim, J Kukreja; (VI) Manuscript writing: All \\ authors; (VII) Final approval of manuscript: All authors. \\ Correspondence to: Simon P. Kim, MD, MPH. Division of Urology, University of Colorado Anschutz Medical Center, 12631 E. 17th Avenue, M/S \\ 391, Aurora, Colorado 80045, USA. Email: simon.kim@ucdenver.edu.
}

\begin{abstract}
Radical prostatectomy $(\mathrm{RP})$ has undergone a remarkable transformation from open to minimallyinvasive surgery over the last two decades. However, it is important to recognize there is still conflicting evidence regarding key outcomes. We aimed to summarize current literature on comparative effectiveness of robotic and open RP for key outcomes including oncologic results, health-related quality of life (HRQOL) measures, safety and postoperative complications, and healthcare costs. The bulk of the paper will discuss and interpret limitations of current data. Finally, we will also highlight future directions of both surgical approaches and its potential impact on health care delivery.
\end{abstract}

Keywords: Comparative effectiveness research; outcomes; prostate cancer; open; radical prostatectomy (RP); robotics; surgery

Submitted May 02, 2019. Accepted for publication Nov 27, 2019.

doi: $10.21037 /$ tau.2019.12.01

View this article at: http://dx.doi.org/10.21037/tau.2019.12.01

\section{Introduction}

Prostate cancer $(\mathrm{PCa})$ is the most commonly diagnosed solidorgan tumor in males with estimated 164,690 new cases in 2018 (1). Over the past decade, the incidence of prostate cancer in the United States has declined by approximately $31 \%$ which is attributable to the changes from the U.S. Preventive Task Force (1-3). Despite the lower incidence of PCa in recent years, it has been demonstrated that there has been a modest increase in adverse pathologic features with higher Gleason score and non-organ confined disease $(4,5)$. Against this backdrop, clinical practice guidelines universally recommend surgery as an acceptable treatment alternative in appropriately selected men diagnosed with intermediate or high-risk prostate cancer and a greater than 10-year life expectancy (6-9).

Radical prostatectomy (RP) has long been established as an effective primary treatment option for patients diagnosed with clinically localized prostate cancer $(6,9,10)$. RP has been clearly shown to confer a survival benefit in appropriately selected patients (11). It has been demonstrated to offer excellent oncological outcomes, with cancer-specific survival approaching $95 \%$ at 15 years, though concerns remain on overtreatment and healthrelated quality of life (HRQOL) complications from urinary incontinence and erectile dysfunction (11-13). A key goal for all primary therapies revolves around oncologic outcomes and minimizing adverse HRQOL effects. For RP, the trifecta of achieving negative margins, retaining urinary continence and preserving erectile function has been put forward as measure for surgical quality and comparative effectiveness $(12,13)$.

Against this back drop, RP has undergone a remarkable transformation from open to minimally-invasive surgery over the last two decades $(14,15)$. Roboticassisted laparoscopic radical prostatectomy (RALP) has 
become more readily adopted now eclipsing open radical prostatectomy (ORP) as the predominant surgical approach for localized prostate cancer (16-18). However, it is essential to recognize that FDA approval and subsequent rapid adoption of robotic RP occurred largely based on observational data in absence of a clinical randomized trial (19).

It is therefore crucial to examine the comparative effectiveness of robotic and open RP, especially at a time when key stakeholders in our health care system have greater scrutiny on outcomes, quality of care, and costs in the context of value-based healthcare. Critically assessing differences on outcomes and costs for open and robotic $\mathrm{RP}$ are needed to better inform and implement health care policy. In this context, we aimed to comprehensively review the comparative effectiveness of ORP and RALP for key outcomes including oncologic outcomes, HRQOL, safety and postoperative complications, and healthcare costs. We will also highlight future directions of both surgical approaches and its potential impact on patient-centered outcomes and health care delivery.

\section{Oncologic outcomes}

The principal objectives of RP aim to completely excise the cancer to achieve long-term cancer control and minimize need for adjuvant therapies, while preserving HRQOL. While RP was initially introduced in the early 1900's as a primary therapy for localized PCa via open or perineal approaches, two major advances revolutionized this surgery. Prior to these advance, RP was associated with significant peri-operative morbidity for significant blood loss, adjacent organ injury (rectal or ureteral injury), and death as well as long-term HRQOL with high rates of urinary incontinence and erectile dysfunction (20). The first modification in the technique for ORP involved a retropubic approach allowing for better exposure to perform a concomitant pelvic lymphadenectomy and identification of key anatomic structures such as dorsal venous complex (DVC) and the neurovascular bundles (NVB) (21). The second major advance in RP came from Walsh and colleagues, where they defined the importance of controlling the DVC, identifying the NVB, and performing nerve-sparing during surgery (22). Meticulous dissection and controlling the DVC provided significant lower blood loss and better visualization for other key parts of ORP. Equally important, preservation of the NVB markedly changed the HRQOL implications regarding erectile dysfunction, while also not compromising cancer control (23). Indeed, these advances markedly increased the use of ORP as a safe and effective treatment alternative for men diagnosed with localized PCa.

With these technical advances in ORP, many contemporary studies have shown it can provide durable oncologic outcomes (Table 1) (23-29). Several studies have found high long-term cancer specific survival is achievable up to 30 years after surgery (30). For instance, one study found approximately $85 \%$ cancer-specific survival at a median of 15 years following surgery (23). In one of the largest single surgeon ORP retrospective reviews, Mullins et al. demonstrated the 25 -year progression-free, metastasis-free and CCS rates to be $68 \%, 84 \%$ and $86 \%$, respectively (30). In a study including 752 patients with a mean follow-up of 11.7 years, Porter et al. reported on prostate cancer specific survival, prostate specific antigen progression-free survival, and overall survival which ranged from $99.0 \%$ to $81.5 \%, 84.8 \%$ to $54.5 \%$, and $93.5 \%$ to $19.3 \%$, respectively (29).

Wilt et al. also performed the first systematic review and meta-analysis of different disease management strategies for localized prostate cancer (31).

When compared to WW, ORP reduced cancerrelated mortality $(10 \%$ vs. $15 \% ; \mathrm{P}=0.01)$ and distant metastasis $(15.2 \%$ vs. $25.4 ; \mathrm{P}<0.05)$, but $\mathrm{ORP}$ and primary radiotherapy were associated with substantive impact on urinary outcomes and erectile dysfunction. However, two multi-centered randomized clinical trials on watchful waiting and RP showed mixed results in improving overall survival from localized PCa. The Scandinavian Prostate Cancer Study Number 4 (SPCG 4), randomly allocated 695 men and demonstrated an absolute decrease in death from prostate cancer of $11.7 \%$ in the surgery arm in most recent update of outcomes with a median follow-up of 23.6 years. The number of needed to treat to prevent one death required 8.4 patients to undergo surgery (32). On the other hand, the Prostate Cancer Intervention versus Observation Trial (PIVOT) randomized 731 patients at VA hospitals in the US (33). At a median follow-up of 10 years, the study found no statistically significant difference in cancer-specific and overall survival, though men in the surgical treatment arm had a lower hazard ratio for developing bone metastasis (HR: 0.4 ; $\mathrm{P}<0.001$ ). It is noteworthy that both trials accrued patients during the ORP era. Taken together, a plausible inference is that ORP is modestly effective in reducing the morbidity of distant metastasis from prostate cancer.

It is essential to acknowledge that cancer control varies 
Table 1 Summary of contemporary studies providing pathologic features among patients undergoing ORP

\begin{tabular}{|c|c|c|c|c|c|c|c|c|c|c|}
\hline Study & $\mathrm{n}$ & $\begin{array}{c}\text { Gleason } \\
6(\%)\end{array}$ & $\begin{array}{c}\text { Gleason } \\
7(\%)\end{array}$ & $\begin{array}{l}\text { Gleason } \\
8-10(\%)\end{array}$ & $\begin{array}{l}\text { pT2 } \\
(\%)\end{array}$ & $\begin{array}{l}\text { pT3 } \\
(\%)\end{array}$ & $\begin{array}{l}\text { PSM } \\
(\%)\end{array}$ & $\begin{array}{l}\text { BDFS } \\
(\%)\end{array}$ & $\begin{array}{l}\text { CSS } \\
(\%)\end{array}$ & $\begin{array}{l}\text { Mean follow-up } \\
\text { (years) }\end{array}$ \\
\hline Lepor et al., 2001 (24) & 1,000 & 54.3 & 36.5 & 9.2 & 76.6 & 21.6 & 19.9 & - & - & - \\
\hline Augustin et al., 2003 (25) & 1,243 & 47.6 & 51 & 1.4 & 67 & 31.6 & 21.4 & - & - & - \\
\hline Chun et al., 2006 (28) & 4,277 & 44.6 & 53.3 & 2.1 & 64.3 & 34.2 & 21.5 & 61 & - & 2.61 \\
\hline Porter et al., 2006 (29) & 752 & 69 & 22.6 & 8.4 & 54.6 & 0.5 & 37.6 & - & 81.5 & 11.7 \\
\hline
\end{tabular}

ORP, open radical prostatectomy; PSM, positive surgical margins; BDFS, biochemical disease free-survival; CSS, cancer specific survival.

with clinical and pathologic risk factors. Independent clinical prognostic factors are tumor stage, Gleason score, preoperative PSA level, and treatment. Adverse pathology features include non-organ-confined disease, extracapsular extension, lymph vascular invasion, positive surgical margins (PSM), lymph node involvement, and seminal vesicle invasion. This also varied considerably when comparing the pre to the post-PSA eras, with modest stage migration and improvement in treatment outcomes after the advent and widespread use of PSA $(30,34)$. Another critical factor for oncologic outcomes is achieving negative margins from RP. Most studies demonstrate PSM in 11$38 \%$ of patients who undergo RP in contemporary open series (35). This is important because PSM increases not only the risk of biochemical recurrence (BCR), but also the need for secondary cancer treatments (35). In organconfined tumors the rate of positive margins varied between $3-7 \%$ on the largest open prostatectomy series reported to date (36-41). On the other hand, when including patients with non-organ confined disease, the rates of positive margin increased to $17.2-40 \%$ (36-41). It's been recognized to be particularly important to achieve negative margins in the presence of other adverse pathological features, in particular unfavorable Gleason score cancers (38).

RALP was introduced in the early 2000 rapidly disseminating over the last two decades (42). At the time of its introduction, commonly cited benefits included ability to achieve minimally-invasive surgery, better magnification to allow for a more meticulous dissection, and articulation of surgical instruments to allow for intracorporeal suturing. As a consequence, it was felt that RALP may lead to lower rates of PSM and improved oncologic outcomes as well as better functional outcomes $(14,15)$. Unfortunately, there is a paucity of long-term studies on cancer-specific survival compared to ORP to date. However, most of recent data and comparisons have relied on outcomes for PSM and BCR, which are summarized in Table 2 (43-50).

Retrospective studies have shown mixed results on the rates of PSM and BCR for ORP and RALP (51-54). Several studies have shown RALP was associated with lower PSM rates relative to ORP $(52,53)$. Moran et al. reported on data derived from 15 studies including almost 3,000 patients and showed that RALP was associated with fewer PSM for organ-confined tumors (RR 0.63; 95\% CI, 0.49-0.81, $\mathrm{P}<0.001)(53)$. Thompson et al. reported on 2,206 consecutive patients who underwent either ORP or RALP for localized PCa and found a direct relationship between surgical volume and PSM and BCR rates (52). Interestingly, PSM were initially higher for the initial cases of RALP than for ORP (OR 6.13; 95\% CI, 1.95-19), but then decreased and became lower as the case volume increased suggesting a learning cover (OR 0.66; 95\% CI, 0.42-1.02). Trends in BCR also mirrored lower relapses evident in RALP compared to ORP amongst more cases at the end of series (HR 0.65; 95\% CI, 0.47-0.90). Similarly, Hu et al showed that RALP was associated with lower PSM compared to ORP for intermediate $(21.0 \%$ vs. $15.0 \%$; OR: 0.66 ; $95 \%$ CI, $0.59-0.75)$ and high-risk disease (20.6\% vs. $15.1 \%$; OR: $0.70 ; 95 \%$ CI, 0.63-0.77) $(14,42)$. Moreover, RALP was associated with lower need for adjuvant treatments at 6 , 12 , and 24 months postoperatively (14). Importantly, this was a community-based study which may actually reflect the scenario where most of the RPs are performed in the country.

Several contemporary studies have shown that RALP have comparable oncologic outcomes relative to ORP in 
Table 2 Summary of contemporary studies providing pathologic features among patients undergoing RALP

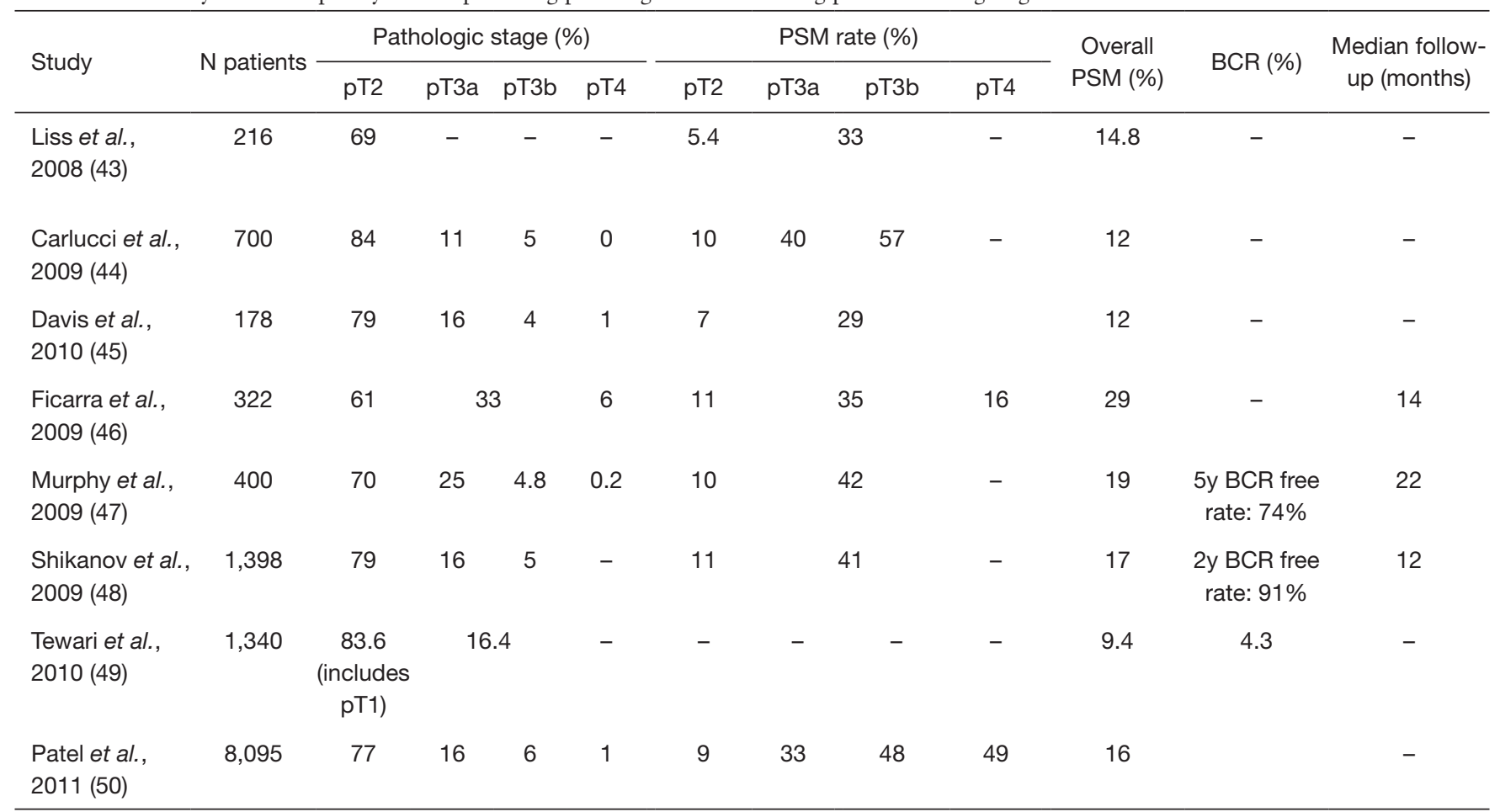

PSM, positive surgical margin; f/u, follow-up.

the post-dissemination era. Gandaglia et al. studied a similar population from the SEER-Medicare linked database in the post dissemination era and found that neither surgical approach was associated with increased use of adjuvant treatments (15). Moreover, two systematic reviews supported these findings in that PSMs have improved, where contemporary PSM rates for RALP are 15\% (6-32\%) overall and $9 \%$ in pathologically localized disease $(55,56)$. For instance, overall rates of PSM were RALP when compared to ORP were similar overall (OR: $1.21 ; \mathrm{P}=0.19)$ and for pT2 PSM rates (OR: $1.25 ; \mathrm{P}=0.31)$ as well as $\mathrm{BCR}$ free rates (HR: 0.9; $\mathrm{P}=0.52$ ).

While these studies have demonstrated similar and possibly better pathologic outcomes attributable to RALP, it is essential to acknowledge that all of the aforementioned studies relied on observational studies, thereby raising concerns about selection bias and causal inferences. This was recently addressed by randomized clinical trial (18). In this study, patients were enrolled based on an incident diagnosis of clinically localized prostate cancer and aged 35 and 70 years old with an estimated life expectancy of greater than 10 years; and then randomly allocated with either RALP or ORP. At the start of the study, the RALP surgeon had completed a 2-year fellowship, and 200 robotic procedures whereas the ORP surgeon had been in practice for 15 years and performed 1,500 prostatectomies.

Oncological outcome was evaluated by BCR (PSA $\geq 0.2 \mathrm{ng} / \mathrm{mL}$ ) and evidence of progression on imaging studies during the 24 months (18). A total of 151 in the ORP group and 157 patients in the RALP group proceeded to surgery. At a median follow-up of 24 months, there were 13 BCR in the ORP arm compared to four in the RALP group, even though the two proportions were only deemed different on a superiority test analysis $(\mathrm{P}=0.019)$. The two groups were not significantly different in regard to evidence of disease progression on imaging studies $(\mathrm{P}=0.29)$. Finally, both techniques also showed equivalence in the proportion of PSM, $10 \%$ in the ORP group vs. $15 \%$ in the RALP group $(\mathrm{P}=0.21)$. These findings provide a stark contrast from the earlier observational studies. One safe inference is that RALP is likely similar to ORP for efficacy for treating localized $\mathrm{PCa}$; however, there are little data to suggest that is superior.

\section{Functional outcomes}

An equally important outcome in assessing the comparative 
effectiveness of RALP and ORP include functional outcomes and HRQOL regarding urinary continence and sexual function. It is well established that many of the local therapies for localized PCa adversely affect HRQOL for patients experiencing urinary leakage and erectile dysfunction (57-63). With the advances of ORP with control of the DVC as well as meticulous preservation of the NVB, HRQOL improved amongst PCa patients undergoing surgery in the pre-robotic surgery era. Furthermore, developing validated QOL instruments to formally assess patient-reported outcomes have become an indicator for quality of care and standardized to a large degree across urologic practices in the United States $(7,8)$. Key leading examples of validated instruments to assess HRQOL specific for prostate cancer and its associated treatments include the Expanded Prostate Cancer Index (EPIC) composite and the UCLA Prostate Cancer Index, amongst others (64-69).

Data on patient-reported outcome measures after treatment of localized PCA have matured significantly in the last 20 years $(58,59,70-72)$. Importantly, RP has been shown to have the highest impact on urinary control compared to radiotherapy and active surveillance (70). Indeed, a recent report on patient-reported outcomes among 1,643 men enrolled in the Prostate Testing for Cancer and Treatment trial (Protec T) showed that RP had the highest adverse effect on urinary continence at 6 months, with the rate of incontinence increasing from $1 \%$ at baseline to $46 \%$ at 6 months (70). This rate subsequently improved so that by year $6,17 \%$ were still using pads. Similarly, among 1,164 men enrolled in the Prostate Cancer Outcomes Study (PCOS) who underwent RP, $18.3 \%$ reported no control or frequent urinary leakage and $17.1 \%$ were bothered by dripping at 15 years (58).

The adverse effect of prostatectomy on potency is also greatest at the first 2 years after surgery, particularly at 6 months postoperatively (70). Sexual function among patients enrolled in the Protec T trial was markedly reduced from baseline to 6 months, with rates of erectile dysfunction varying from $67 \%$ to $12 \%$, respectively (70). Erectile function remained worse at all time points, slightly improving to $21 \%$ with erections firm enough for intercourse at 36 months, but again declining to $17 \%$ at 6 years (70). When compared to watchful waiting, $\mathrm{RP}$ also entails a higher risk of erectile dysfunction $(70,71)$. Erections were seldom or never sufficient for intercourse in $80 \%$ of men who underwent RP compared to $45 \%$ of those on watchful waiting in the Scandinavian Prostatic Cancer Group Study Number 4 (71). Among men enrolled in the PCOS trial, erectile dysfunction was almost universal after RP, with rates varying from $78.8 \%$ to $87.0 \%$ at 2 and 15 years after surgery, respectively (58).

It is important to emphasize that these data came from patients who underwent either ORP or were operated on by surgeons on the beginning of their learning curve for RALP, before the widespread dissemination of robotic surgery (58,59,70-72). Therefore, in order to fully understand the impact of minimally invasive surgery on functional outcomes, a detailed analysis of the literature on reported HRQOL outcomes in the post-implementation era is of outmost importance.

The introduction of robotic surgery heralded the potential to achieve minimally-invasive surgery and improve better visualization with 3-dimensional magnification as well as intra-corporeal suturing. In theory, the combination of these advances would allow for more meticulous dissection in order to achieve better functional outcomes and HRQOL $(17,73,74)$.

A metanalysis reported on the prevalence of urinary continence following RALP after the widespread dissemination of minimally invasive surgery and when most surgeons from high-volumes centers had already gained extensive experience with the technique (73). Urinary incontinence rates ranged from $4 \%$ to $31 \%$, with a mean value of $16 \%$ at 12 -month follow-up (73). When compared to open series on the same period, the risk of urinary incontinence was $11.3 \%$ after ORP and $7.5 \%$ after RALP. The cumulative analysis showed a statistically significant advantage in favor of RALP at 12 months after surgery (OR: 1.53; 95\% CI, 1.04-2.25; $\mathrm{P}=0.03$ ) (73). These data must be interpreted with caution since most of the series were level of evidence 3 or 4 and all of them came from centers of excellence where high-volume surgeons were performing all the operations.

Recent data, which included a prospective nonrandomized trial and a prospective randomized study, have shown different continence results when compared to previous observational studies $(17,18)$. In the nonrandomized study, there were no statistical difference in incontinence rates between groups at 12 months. Following ORP, $144(20.2 \%)$ men were incontinent, as were 366 $(21.3 \%)$ after RALP. The adjusted odds-ratio was 1.08 (95\% CI, 0.87-1.34) (17). Similarly, the prospective and randomized study did not show any significant differences in urinary function scores between the ORP and RALP groups at 6 weeks post-surgery $(74.5$ vs. $71.1 ; \mathrm{P}=0.09)$ or 12 weeks post-surgery (83.8 vs. $82.5 ; \mathrm{P}=0.48)(18)$. Their 
most recent updated results after 24 months of followup again did not demonstrate any significant difference between both surgical modalities regarding continence recovery (75).

Recovery of erectile function after RP is a difficult outcome to compare due to the multiple variables involved in potency preservation (16,17,74,76-78). Multiple studies have found that age at surgery, baseline erectile function before surgery, and performance of a nervesparing procedure were independent predictor factors of potency recovery following surgery $(72,74)$. Moreover, the definition of erectile dysfunction after surgery and the quality of reported data varies considerably in the literature (16,17,74,76-78).

On a recent systematic review which included multiple observational reports, Ficarra et al. showed better 12-month potency rates after RALP in comparison with ORP (OR: 2.84; 95\% CI, 1.46-5.43; $\mathrm{P}=0.002$ ), with potency ranging from $54 \%$ to $90 \%$ at 12 and 24 months, respectively (78). Subsequently, Haglind et al. reported a very high rate of erectile dysfunction following surgery on their prospective non-randomized study (17). Erectile dysfunction was observed in $70.4 \%$ and $74.7 \%$ of men at after RALP and ORP, respectively at 12 -month follow-up. The adjusted OR was 0.81 (95\% CI, 0.66-0.98) (17).

Rates of positive margin and potency recovery are intrinsically linked $(77,79)$. Yuh et al. reviewed 1,360 patients who underwent RALP for high-risk PCa with a follow-up of 9.7-37.7 months and reported a potency recovery at 12 months after RALP of only $52 \%$ to $60 \%(79)$. This fact became even clearer after a prospective non-randomized Swedish trial showed opposite rates of PSMs and potency recovery after RP (77). In this study the degree or nerve-bundle preservation correlated with PSMs and potency rates. In pT2 tumours, $10 \%$ versus $17 \%$ PSM rates were observed for open and RALP, respectively. Patients who underwent RALP had better potency results compared to those who underwent ORP for organ-confined disease at 12 and 24 months. On the other hand, corresponding rates of PSM for pT3 tumors were $48 \%$ and $33 \%$, respectively. There was a trend towards better erectile function recovery on the ORP compared to the RALP (77). There will always be a tradeoff between potency preservation and cancer control. Moreover, surgeon experience is of paramount importance in achieving trifecta even though multiple other variables intrinsic to the patients come into play and may influence negatively the rates of potency recovery after RP, irrespective of the employed surgical modality $(16,17,74,76-78)$.
Besides all the recent advances in technique refinement, post-surgery care, and penile rehabilitation protocols observed in the last decade, erectile dysfunction still poses significant bother to patients undergoing RP for PCa (58,59,70-72). Most recently, Capogrosso et al. reported on long-term functional outcomes regarding recovery of erectile function following surgery at Memorial Sloan Kettering Cancer Center (16). The authors hypothesized significant improvements in potency rates after RP would be expected due to several technical advances observed in the last decade. However, they observed a significant decrease in potency rates at both 12 and 24 months after surgery $(\mathrm{P}=0.01)(16)$. Even after adjusting for age at surgery, baseline functional parameters, and type of surgery, year of surgery was not associated with potency recovery (12 months, $\mathrm{P}=0.4 ; 24$ months, $\mathrm{P}=0.3$ ) (16). Although controversial, it is probable that due to the implementation of active surveillance and the consequent shift towards treating more aggressive prostate cancer, patients undergoing RP are now older, have worse baseline erectile function, and poorer health status (16). Considering the strong association of these factors and the risk of postoperative erectile dysfunction, it is probable that patients treated in recent years were unlikely to benefit from more precise surgical technique and rehabilitation measures $(16,68,78)$.

\section{Safety, postoperative complications, patient reported outcomes, and healthcare costs}

Critically assessing the comparative effectiveness of ORP and RALP also requires evaluating patient safety, postoperative complications, patient-reported outcomes and costs. Policy-makers and key stakeholders weigh these important considerations in assess the adoption and support of new health care technologies. In early adoption, robotic surgery appeared to be associated with a higher rate of genitourinary complications $(4.7 \%$ vs. $2.1 \% ; \mathrm{P}=0.001)$ when compared to open surgery in the pre-dissemination era (42). On the other hand, this population-based study indicated that minimally invasive robotic surgery was associated with lower rates of blood transfusions $(2.7 \% \mathrm{vs}$. $20.8 \%$; $\mathrm{P}<0.001)$, anastomotic stricture $(5.8 \%$ vs. $14.0 \%$; $\mathrm{P}<0.001$ ), overall surgical complications ( $4.3 \%$ vs. $5.6 \%$; $\mathrm{P}=0.03$ ), and shorter length of stay (median, $2.0 \mathrm{vs.} 3.0$ days; $\mathrm{P}<0.001)$ (42). Other population-based studies reported similar findings regarding the differences in the rates of complications, LOS, and blood transfusion concerning the possible benefits of RALP over ORP $(42,80-84)$ (Table 3). 
Table 3 Perioperative complications of open $v s$. minimally invasive surgery for prostate cancer in population-based studies

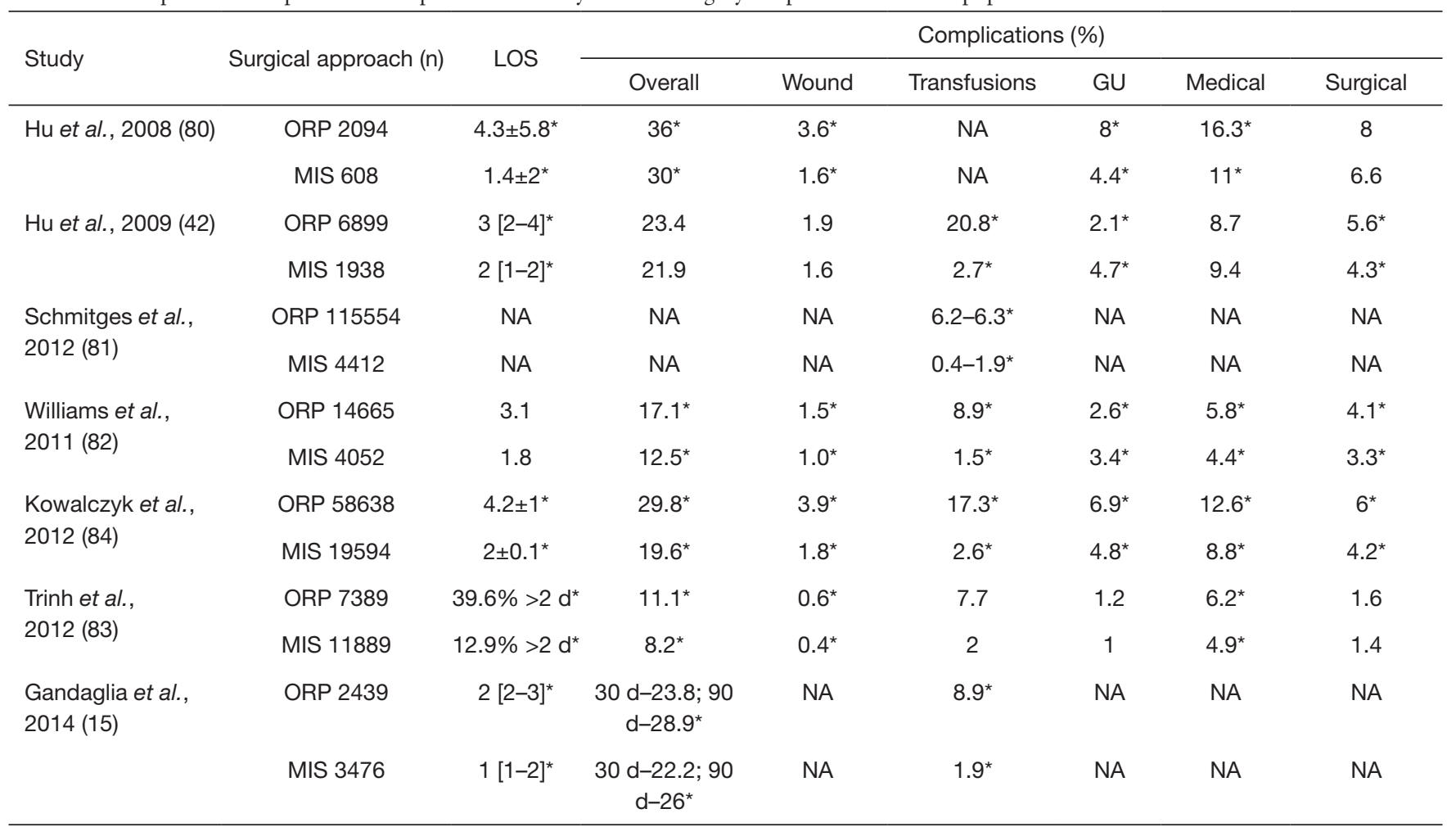

${ }^{*}$, statistically significant. LOS, length of hospital stays.

Overall, these studies suggested that RALP had favorably low rates of medical complications (8-20\%), surgical complications (1.4-4.7\%), and low blood transfusion (2\%). Once adjusted for different covariates, MIS was associated with lower overall complication rates, and lower transfusion rates compared with ORP (42,80-84).

Further assessments of RALP utilization in the post-dissemination era had shown a clear advantage of RALP over ORP for multiple perioperative parameters $(80,83,85)$. In the Nationwide Inpatient Sample (NIS), RALP was associated with decreased cardiac $(0.9 \%$ vs. $1.3 \%, \mathrm{P}=0.007)$, respiratory $(1.2 \%$ vs. $2.6 \%, \mathrm{P}=0.001)$, vascular $(0.4 \%$ vs. $0.6 \%, \mathrm{P}=0.019)$, and operative wound complications $(0.4 \%$ vs. $0.6 \%, \mathrm{P}=0.031)$ (83). There was no difference in genitourinary complications (urinary leaks and bladder neck contractures between techniques $(1.0 \%$ vs. $1.2 \%, \mathrm{P}=0.3)(83)$. In a propensity scorematched analysis, ORP was found to have higher rates of prolonged hospitalization (39.6\% vs. $14.5 \%$, respectively, $\mathrm{P}<0.001)$ and in-hospital mortality (OR: 0.10; 95\% CI, $0.01-0.86, \mathrm{P}=0.036$ ) (83). A recent sub analysis of the Laparoscopic Prostatectomy Robotic Open (LAPPRO) study, a multicenter prospective controlled trial, looked into predictors of deep vein thrombosis (DVT) and pulmonary embolism (PE) (86). In addition to a previous history of thrombosis, locally advanced disease, grade group disease 4 or greater, ORP and lymph node dissection were associated with a higher risk of DVT/PE compared to RALP (86). Moreover, ORP increased the risk of DVT/PE 3.8-fold compared to RALP among patients who did not undergo lymphadenectomy (86).

Reducing hospital readmissions represent a key initiative to help improve patient outcomes and reduce health care costs $(42,85,87,88)$. As a result, further scrutiny on techniques associated with less postoperative morbidity is imperative. Using the National Surgical Quality Improvement Program (NSQIP), Pilecki et al. analyzed 5,471 patients who underwent either RALP [4,374, (79.9\%)] or ORP $[1,097,(20.1 \%)]$ and found that minimally invasive surgery conferred lower readmission rates compared to ORP (3.48\% vs. 5.47\%, respectively; $\mathrm{P}=0.002$ ) (88). Analysis of propensity matched cohorts from the National Cancer Data Base (NCDB) showed RALP was associated with lower probability of 30 -day readmission $(\mathrm{OR} 0.82, \mathrm{P}<0.001)$ 
and 30-day mortality (OR 0.45, P=0.001) (87).

There is some uncertainty about patient-reported outcomes, in particular convalescence and recovery. Some studies have shown robotic surgery have less postoperative pain and quicker recovery $(89,90)$. However, patient generally reported low pain irrespective of the surgical approach, and RALP may not deliver a meaningful reduction in pain compared to ORP (91). It is feasible that robotic surgery may confer a quicker return to work. In a study including 1,415 men from a high-volume European center, surgical approach showed no impact on return to work time (RALP vs. ORP hazard ratio $=1$; 95\% CI, 0.911.16, $\mathrm{P}=0.69$ ) (92). On the other hand, a recent analysis conducted in Sweden did show men who underwent RALP returned to work after a median of 35 days compared to 48 days after ORP $(\mathrm{P}<0.001)(90)$. There is clearly a need for prospective data comparing both techniques in order to better evaluate pain and recovery after surgery (90).

In this era of value-based medicine, robotic surgery has been shown to have greater health care costs compared to open surgery $(85,93,94)$. A recent study reported on hospitalization costs for RP due to robotic surgery and showed that RALP is associated with higher hospitalization costs compared to ORP, in spite of having lower LOS and postoperative complications (94). In this study, RALP had higher median and adjusted difference in total costs from hospitalization of $\$ 1,547$ and $\$ 2,542$, respectively. Subsequently, Leow et al. reported on direct hospital costs for both ORP and RALP on a cohort of men from the Premier Hospital Database from 2003 to 2013 (85). Overall, the direct hospital costs were higher for RALP within 90 days after surgery $(+\$ 4,528, \mathrm{P}<0.001)$. Interestingly, cost did not differ between techniques among high-volume surgeons (104 cases/year; $+\$ 1,990, \mathrm{P}=0.40$ ) and highest-volume hospitals (318 cases/year; $+\$ 1,225, \mathrm{P}=0.39$ ) (85). Although currently unclear and yet to be further studied in long-term prospective comparative studies, it may also be the case that RALP is associated with higher short-term upfront costs but lower long-term expenditures due to lower readmission and complication rates, especially when performed by skilled surgeons at centers of expertise $(83,85,88,94)$.

\section{Future directions}

Accuracy and integrity in the conduction of research are crucial for the report of unbiased results, as the debate between RALP and ORP evolves (95). More recently, multiple studies have highlighted the potential influence of industry support on surgical studies, particularly on robotic surgery $(96,97)$. A systematic review of both randomized controlled trials and observational studies comparing the efficacy of the da Vinci on clinical outcomes showed that nearly all (91\%) included studies had authors who received financial conflict of interest (COI) payments, who were ultimately more likely to report positive robotic surgery outcomes (97). Moreover, there is growing evidence that self-report COI statements might not be entirely accurate. On a recent study where investigators compared author's declared COI with data found on "open payments database", multiple unreported payments and incongruities were encountered (96). Therefore, it is our impression that not only journals but more importantly class organizations should include a detailed report on financial disclosures in published manuscripts and guidelines, in order to account for COI disbursements received by participating authors.

Health care technology continues to evolve. While ORP has long served a key option for surgically treated men with localized PCa, contemporary advances in technique have largely occurred in RALP. For instance, Retzius-sparing and robotic single-port perineal approaches represent examples in the continued evolution of surgical approach $(98,99)$. Retzius-sparing technique of robotic RP has been shown to improve short-term continence results (52). This was further studied on a randomized controlled trial by Mani Menon's group (99). Overall, 48\% versus $71 \%$ of men undergoing surgery were continent 1 week after catheter removal following regular versus Retzius-sparing RALP, respectively $(\mathrm{P}=0.01)$. Median time to continence in Retzius-sparing and regular RALP was 2 and 8 days after catheter removal, respectively $(\mathrm{P}=0.02)$. Even though these are promising continence outcomes, comparison between these and other variables such as PSM and BCR rates need long-term validation before definitive conclusions can be made (100). Single-port RALP has been shown to be feasible and seems to offer similar advantages inherent to all minimally invasive techniques: minimal blood loss, low conversion rate, and low length of hospital stay $(98,101)$. However, further studies comparing perioperative complications and functional outcomes with the conventional multi-port robotic prostatectomy are needed.

Enhanced recovery after surgery (ERAS) represent a health care pathway aimed to improve patient satisfaction, outcomes and convalescence $(102,103)$. Originally described for colorectal surgery, it has been implemented for major urological surgeries with good results (102). In an effort to improve outcomes after RP, the ERAS protocol was implemented in Canada, an universal healthcare system, and the results were recently published (103). It was showed 
that it decreased LOS with no increase in postoperative complications, ER visits post-discharge, or readmissions, irrespective of the type of technique utilized, open or robotic surgery (103). Although focusing primarily on clinical recovery from surgery, implementing ERAS protocols can have a big impact on hospital-related care costs during hospitalization and on costs associated with readmissions $(102,103)$. Ideally, prospective trials should focus on different variables of the ERAS protocol in order to better answer these key questions and encourage widespread adoption of multimodal interventions.

The volume-outcome relationship has long been established where high volume surgeons and hospitals have been shown to have less complications and perioperative mortality. Although the reasoning behind the volumeoutcome relationship remain unclear, this relationship also applies for both approaches of RP. Indeed, a populationbased study has shown higher volume of RP surgeons was associated with less perioperative adverse outcomes, transfusion rates, urinary complications, and prolonged length of stay (104). In a pooled analysis, Wilt et al. showed that men treated at high-volume centers had a $5.30 \%$ lower rate $(95 \% \mathrm{CI},-9.30,-1.30)$ of urinary complications (105). This same group also studied the association between surgeon volume and patient outcomes and found the rate of late urinary complications and incontinence were $2.4 \%$ and $1.2 \%$ lower, respectively (105).

\section{Conclusions}

In this contemporary era of value-based medicine, comparative effectiveness research serves as a critical part in assessing health care delivery and reimbursement for patients, providers and key stakeholders. While RALP has largely become the predominant approach for surgically treated patients diagnosed with localized PCa, it is essential to acknowledge some conflicting results due to study design and era of evaluation (adoption and dissemination of RALP). Most contemporary studies in the post-dissemination era have suggested that RALP has shorter LOS, less post-operative complications and blood transfusion, whereas oncologic outcomes seem to be equivalent. However, RALP has been shown to have higher hospitalization costs. As a consequence, greater attention to use of RALP and healthcare costs will likely occur. To that end, urologic surgeons will need to address these concerns by identifying ways to reduce health care costs and develop new approaches to improve functional outcomes for this prevalent malignancy.

\section{Acknowledgments}

Funding: None.

\section{Footnote}

Provenance and Peer Review: This article was commissioned by the Guest Editors (Marc C. Smaldone and Jeffrey J. Tomaszewski) for the series "Controversies in Minimally Invasive Urologic Oncology" published in Translational Andrology and Urology. The article has undergone external peer review.

Conflicts of Interest: The series "Controversies in Minimally Invasive Urologic Oncology" was commissioned by the editorial office without any funding or sponsorship. Dr. Simon P. Kim funded through a career development award from the Conquer Cancer Foundation and the American Society of Clinical Oncology (ASCO) and funded as a coprincipal investigator for MD12-003. The authors have no other conflicts of interest to declare.

Ethical Statement: The authors are accountable for all aspects of the work in ensuring that questions related to the accuracy or integrity of any part of the work are appropriately investigated and resolved.

Open Access Statement: This is an Open Access article distributed in accordance with the Creative Commons Attribution-NonCommercial-NoDerivs 4.0 International License (CC BY-NC-ND 4.0), which permits the noncommercial replication and distribution of the article with the strict proviso that no changes or edits are made and the original work is properly cited (including links to both the formal publication through the relevant DOI and the license). See: https://creativecommons.org/licenses/by-nc-nd/4.0/.

\section{References}

1. Siegel RL, Miller KD, Jemal A. Cancer statistics, 2018. CA Cancer J Clin 2018;68:7-30.

2. Siegel R, Naishadham D, Jemal A. Cancer statistics, 2013. CA Cancer J Clin 2013;63:11-30.

3. Moyer VA, Force USPST. Screening for prostate cancer: U.S. Preventive Services Task Force recommendation statement. Ann Intern Med 2012;157:120-34.

4. Hoffman RM. Implications of the New USPSTF Prostate Cancer Screening Recommendation-Attaining Equipoise. JAMA Intern Med 2018;178:889-91.

5. Blair BM, Robyak H, Clark JY, et al. Impact of United 
States Preventive Services Task Force recommendations on prostate biopsy characteristics and disease presentation at a tertiary-care medical center. Prostate Int 2018;6:110-4.

6. Sanda MG, Cadeddu JA, Kirkby E, et al. Clinically Localized Prostate Cancer: AUA/ASTRO/SUO Guideline. Part I: Risk Stratification, Shared Decision Making, and Care Options. J Urol 2018;199:683-90.

7. Sanda MG, Cadeddu JA, Kirkby E, et al. Clinically Localized Prostate Cancer: AUA/ASTRO/SUO Guideline. Part II: Recommended Approaches and Details of Specific Care Options. J Urol 2018;199:990-7.

8. Carroll PH, Mohler JL. NCCN Guidelines Updates: Prostate Cancer and Prostate Cancer Early Detection. J Natl Compr Canc Netw 2018;16:620-3.

9. Mottet N, Bellmunt J, Bolla M, et al. EAU-ESTROSIOG Guidelines on Prostate Cancer. Part 1: Screening, Diagnosis, and Local Treatment with Curative Intent. Eur Urol 2017;71:618-29.

10. Carroll PR, Parsons JK, Andriole G, et al. NCCN Guidelines Insights: Prostate Cancer Early Detection, Version 2.2016. J Natl Compr Canc Netw 2016;14:509-19.

11. Bill-Axelson A, Holmberg L, Garmo H, et al. Radical Prostatectomy or Watchful Waiting in Early Prostate Cancer. N Engl J Med 2014;370:932-42.

12. Salomon L, Saint F, Anastasiadis AG, et al. Combined reporting of cancer control and functional results of radical prostatectomy. Eur Urol 2003;44:656-60.

13. Eastham JA, Scardino PT, Kattan MW. Predicting an optimal outcome after radical prostatectomy: the trifecta nomogram. J Urol 2008;179:2207-10; discussion 10-1.

14. Hu JC, Gandaglia G, Karakiewicz PI, et al. Comparative effectiveness of robot-assisted versus open radical prostatectomy cancer control. Eur Urol 2014;66:666-72.

15. Gandaglia G, Sammon JD, Chang SL, et al. Comparative effectiveness of robot-assisted and open radical prostatectomy in the postdissemination era. J Clin Oncol 2014;32:1419-26.

16. Capogrosso P, Vertosick EA, Benfante NE, et al. Are We Improving Erectile Function Recovery After Radical Prostatectomy? Analysis of Patients Treated over the Last Decade. Eur Urol 2019;75:221-8.

17. Haglind E, Carlsson S, Stranne J, et al. Urinary Incontinence and Erectile Dysfunction After Robotic Versus Open Radical Prostatectomy: A Prospective, Controlled, Nonrandomised Trial. Eur Urol 2015;68:216-25.

18. Yaxley JW, Coughlin GD, Chambers SK, et al. Robot- assisted laparoscopic prostatectomy versus open radical retropubic prostatectomy: early outcomes from a randomised controlled phase 3 study. Lancet 2016;388:1057-66.

19. Navaratnam A, Abdul-Muhsin H, Humphreys M. Updates in Urologic Robot Assisted Surgery. F1000Res 2018;7.

20. Catalona W, Scott W. Carcinoma of the prostate. Campbell's Urology. Philadelphia: WB Saunders Company, 1986.

21. Walsh PC, Lepor H. The role of radical prostatectomy in the management of prostatic cancer. Cancer 1987;60:526-37.

22. Reiner WG, Walsh PC. An anatomical approach to the surgical management of the dorsal vein and Santorini's plexus during radical retropubic surgery. J Urol 1979;121:198-200.

23. Han M, Partin AW, Pound CR, et al. Long-term biochemical disease-free and cancer-specific survival following anatomic radical retropubic prostatectomy. The 15 -year Johns Hopkins experience. Urol Clin North Am 2001;28:555-65.

24. Lepor H, Nieder AM, Ferrandino MN. Intraoperative and postoperative complications of radical retropubic prostatectomy in a consecutive series of 1,000 cases. J Urol 2001;166:1729-33.

25. Augustin H, Hammerer P, Graefen M, et al. Intraoperative and perioperative morbidity of contemporary radical retropubic prostatectomy in a consecutive series of 1243 patients: results of a single center between 1999 and 2002. Eur Urol 2003;43:113-8.

26. Roehl KA, Han M, Ramos CG, et al. Cancer progression and survival rates following anatomical radical retropubic prostatectomy in 3,478 consecutive patients: long-term results. J Urol 2004;172:910-4.

27. Bianco FJ, Scardino PT, Eastham JA. Radical prostatectomy: long-term cancer control and recovery of sexual and urinary function ("trifecta"). Urology 2005;66:83-94.

28. Chun FK, Graefen M, Zacharias M, et al. Anatomic radical retropubic prostatectomy-long-term recurrencefree survival rates for localized prostate cancer. World J Urol 2006;24:273-80.

29. Porter CR, Kodama K, Gibbons RP, et al. 25-year prostate cancer control and survival outcomes: a 40-year radical prostatectomy single institution series. J Urol 2006;176:569-74.

30. Mullins JK, Feng Z, Trock BJ, et al. The impact of anatomical radical retropubic prostatectomy on cancer control: the 30-year anniversary. J Urol 2012;188:2219-24. 
31. Wilt TJ, Brawer MK, Jones KM, et al. Radical prostatectomy versus observation for localized prostate cancer. N Engl J Med 2012;367:203-13.

32. Bill-Axelson A, Holmberg L, Garmo H, et al. Radical Prostatectomy or Watchful Waiting in Prostate Cancer 29-Year Follow-up. N Engl J Med 2018;379:2319-29.

33. Wilt TJ, Jones KM, Barry MJ, et al. Follow-up of Prostatectomy versus Observation for Early Prostate Cancer. N Engl J Med 2017;377:132-42.

34. Shariat SF, Khoddami SM, Saboorian H, et al. Lymphovascular invasion is a pathological feature of biologically aggressive disease in patients treated with radical prostatectomy. J Urol 2004;171:1122-7.

35. Yossepowitch O, Bjartell A, Eastham JA, et al. Positive surgical margins in radical prostatectomy: outlining the problem and its long-term consequences. Eur Urol 2009; 55:87-99.

36. Ward JF, Zincke H, Bergstralh EJ, et al. The impact of surgical approach (nerve bundle preservation versus wide local excision) on surgical margins and biochemical recurrence following radical prostatectomy. J Urol 2004;172:1328-32.

37. Eastham JA, Kuroiwa K, Ohori M, et al. Prognostic significance of location of positive margins in radical prostatectomy specimens. Urology 2007;70:965-9.

38. Karakiewicz PI, Eastham JA, Graefen M, et al. Prognostic impact of positive surgical margins in surgically treated prostate cancer: multi-institutional assessment of 5831 patients. Urology 2005;66:1245-50.

39. Pettus JA, Weight CJ, Thompson CJ, et al. Biochemical failure in men following radical retropubic prostatectomy: impact of surgical margin status and location. J Urol 2004;172:129-32.

40. Han M, Partin AW, Chan DY, et al. An evaluation of the decreasing incidence of positive surgical margins in a large retropubic prostatectomy series. J Urol 2004;171:23-6.

41. Swindle P, Eastham JA, Ohori M, et al. Do margins matter? The prognostic significance of positive surgical margins in radical prostatectomy specimens. J Urol 2005;174:903-7.

42. Hu JC, Gu X, Lipsitz SR, et al. Comparative effectiveness of minimally invasive vs open radical prostatectomy. JAMA 2009;302:1557-64.

43. Liss M, Osann K, Ornstein D. Positive surgical margins during robotic radical prostatectomy: a contemporary analysis of risk factors. BJU Int 2008;102:603-8.

44. Carlucci JR, Nabizada-Pace F, Samadi DB. Robotassisted laparoscopic radical prostatectomy: technique and outcomes of 700 cases. Int J Biomed Sci 2009;5:201-8.
45. Davis JW, Kamat A, Munsell M, et al. Initial experience of teaching robot-assisted radical prostatectomy to surgeonsin-training: can training be evaluated and standardized? BJU Int 2010;105:1148-54.

46. Ficarra V, Novara G, Secco S, et al. Predictors of positive surgical margins after laparoscopic robot assisted radical prostatectomy. J Urol 2009;182:2682-8.

47. Murphy DG, Kerger M, Crowe H, et al. Operative details and oncological and functional outcome of roboticassisted laparoscopic radical prostatectomy: 400 cases with a minimum of 12 months follow-up. Eur Urol 2009;55:1358-66.

48. Shikanov S, Song J, Royce C, et al. Length of positive surgical margin after radical prostatectomy as a predictor of biochemical recurrence. J Urol 2009;182:139-44.

49. Tewari AK, Patel ND, Leung RA, et al. Visual cues as a surrogate for tactile feedback during robotic-assisted laparoscopic prostatectomy: posterolateral margin rates in 1340 consecutive patients. BJU Int 2010;106:528-36.

50. Patel VR, Coelho RF, Rocco B, et al. Positive surgical margins after robotic assisted radical prostatectomy: a multi-institutional study. J Urol 2011;186:511-6.

51. Haese A, Knipper S, Isbarn H, et al. A comparative study of robot-assisted and open radical prostatectomy in 10,790 men treated by highly trained surgeons for both procedures. BJU Int 2019;123:1031-40.

52. Thompson JE, Egger S, Böhm M, et al. Superior Biochemical Recurrence and Long-term Quality-oflife Outcomes Are Achievable with Robotic Radical Prostatectomy After a Long Learning Curve-Updated Analysis of a Prospective Single-surgeon Cohort of 2206 Consecutive Cases. Eur Urol 2018;73:664-71.

53. Moran PS, O'Neill M, Teljeur C, et al. Robotassisted radical prostatectomy compared with open and laparoscopic approaches: a systematic review and metaanalysis. Int J Urol 2013;20:312-21.

54. Ilic D, Evans SM, Allan CA, et al. Laparoscopic and robotassisted vs open radical prostatectomy for the treatment of localized prostate cancer: a Cochrane systematic review. BJU Int 2018;121:845-53.

55. Novara G, Ficarra V, Mocellin S, et al. Systematic review and meta-analysis of studies reporting oncologic outcome after robot-assisted radical prostatectomy. Eur Urol 2012;62:382-404.

56. Yossepowitch O, Briganti A, Eastham JA, et al. Positive surgical margins after radical prostatectomy: a systematic review and contemporary update. Eur Urol 2014;65:303-13.

57. Wilt TJ, MacDonald R, Rutks I, et al. Systematic review: 
comparative effectiveness and harms of treatments for clinically localized prostate cancer. Ann Intern Med 2008;148:435-48.

58. Resnick MJ, Koyama T, Fan KH, et al. Long-term functional outcomes after treatment for localized prostate cancer. N Engl J Med 2013;368:436-45.

59. Sanda MG, Dunn RL, Michalski J, et al. Quality of life and satisfaction with outcome among prostate-cancer survivors. N Engl J Med 2008;358:1250-61.

60. Hamdy FC, Donovan JL, Lane JA, et al. 10-Year Outcomes after Monitoring, Surgery, or Radiotherapy for Localized Prostate Cancer. N Engl J Med 2016;375:1415-24.

61. Bruner DW, Pugh SL, Lee WR, et al. Quality of Life in Patients With Low-Risk Prostate Cancer Treated With Hypofractionated vs Conventional Radiotherapy: A Phase 3 Randomized Clinical Trial. JAMA Oncol 2019;5:664-70.

62. Barocas DA, Alvarez J, Resnick MJ, et al. Association Between Radiation Therapy, Surgery, or Observation for Localized Prostate Cancer and Patient-Reported Outcomes After 3 Years. JAMA 2017;317:1126-40.

63. Chen RC, Basak R, Meyer AM, et al. Association Between Choice of Radical Prostatectomy, External Beam Radiotherapy, Brachytherapy, or Active Surveillance and Patient-Reported Quality of Life Among Men With Localized Prostate Cancer. JAMA 2017;317:1141-50.

64. Wei JT, Dunn RL, Litwin MS, et al. Development and validation of the expanded prostate cancer index composite (EPIC) for comprehensive assessment of health-related quality of life in men with prostate cancer. Urology 2000;56:899-905.

65. Wei JT, Dunn RL, Sandler HM, et al. Comprehensive comparison of health-related quality of life after contemporary therapies for localized prostate cancer. J Clin Oncol 2002;20:557-66.

66. Hollenbeck BK, Dunn RL, Wei JT, et al. Neoadjuvant hormonal therapy and older age are associated with adverse sexual health-related quality-of-life outcome after prostate brachytherapy. Urology 2002;59:480-4.

67. Hollenbeck BK, Dunn RL, Wei JT, et al. Determinants of long-term sexual health outcome after radical prostatectomy measured by a validated instrument. J Urol 2003;169:1453-7.

68. Litwin MS, Hays RD, Fink A, et al. Quality-of-life outcomes in men treated for localized prostate cancer. JAMA 1995;273:129-35.

69. Litwin MS, Hays RD, Fink A, et al. The UCLA Prostate Cancer Index: development, reliability, and validity of a health-related quality of life measure. Med Care
1998;36:1002-12.

70. Donovan JL, Hamdy FC, Lane JA, et al. Patient-Reported Outcomes after Monitoring, Surgery, or Radiotherapy for Prostate Cancer. N Engl J Med 2016;375:1425-37.

71. Steineck G, Helgesen F, Adolfsson J, et al. Quality of life after radical prostatectomy or watchful waiting. $\mathrm{N}$ Engl J Med 2002;347:790-6.

72. Hu JC, Elkin EP, Pasta DJ, et al. Predicting quality of life after radical prostatectomy: results from CaPSURE. J Urol 2004;171:703-7; discussion 7-8.

73. Ficarra V, Novara G, Rosen RC, et al. Systematic review and meta-analysis of studies reporting urinary continence recovery after robot-assisted radical prostatectomy. Eur Urol 2012;62:405-17.

74. Patel VR, Abdul-Muhsin HM, Schatloff O, et al. Critical review of 'pentafecta' outcomes after robot-assisted laparoscopic prostatectomy in high-volume centres. BJU Int 2011;108:1007-17.

75. Coughlin GD, Yaxley JW, Chambers SK, et al. Robotassisted laparoscopic prostatectomy versus open radical retropubic prostatectomy: 24-month outcomes from a randomised controlled study. Lancet Oncol 2018;19:1051-60.

76. Barry MJ, Gallagher PM, Skinner JS, et al. Adverse effects of robotic-assisted laparoscopic versus open retropubic radical prostatectomy among a nationwide random sample of medicare-age men. J Clin Oncol 2012;30:513-8.

77. Sooriakumaran P, Pini G, Nyberg T, et al. Erectile Function and Oncologic Outcomes Following Open Retropubic and Robot-assisted Radical Prostatectomy: Results from the LAParoscopic Prostatectomy Robot Open Trial. Eur Urol 2018;73:618-27.

78. Ficarra V, Novara G, Ahlering TE, et al. Systematic review and meta-analysis of studies reporting potency rates after robot-assisted radical prostatectomy. Eur Urol 2012;62:418-30.

79. Yuh B, Artibani W, Heidenreich A, et al. The role of robot-assisted radical prostatectomy and pelvic lymph node dissection in the management of high-risk prostate cancer: a systematic review. Eur Urol 2014;65:918-27.

80. Hu JC, Wang Q, Pashos CL, et al. Utilization and outcomes of minimally invasive radical prostatectomy. J Clin Oncol 2008;26:2278-84.

81. Schmitges J, Sun M, Abdollah F, et al. Blood transfusions in radical prostatectomy: a contemporary population-based analysis. Urology 2012;79:332-8.

82. Williams SB, Prasad SM, Weinberg AC, et al. Trends in the care of radical prostatectomy in the United States from 2003 to 2006. BJU Int 2011;108:49-55. 
83. Trinh QD, Sammon J, Sun M, et al. Perioperative outcomes of robot-assisted radical prostatectomy compared with open radical prostatectomy: results from the nationwide inpatient sample. Eur Urol 2012;61:679-85.

84. Kowalczyk KJ, Levy JM, Caplan CF, et al. Temporal national trends of minimally invasive and retropubic radical prostatectomy outcomes from 2003 to 2007: results from the 100\% Medicare sample. Eur Urol 2012;61:803-9.

85. Leow JJ, Chang SL, Meyer CP, et al. Robot-assisted Versus Open Radical Prostatectomy: A Contemporary Analysis of an All-payer Discharge Database. Eur Urol 2016;70:837-45.

86. Tyritzis SI, Wallerstedt A, Steineck G, et al. Thromboembolic complications in 3,544 patients undergoing radical prostatectomy with or without lymph node dissection. J Urol 2015;193:117-25.

87. Pearce SM, Pariser JJ, Karrison T, et al. Comparison of Perioperative and Early Oncologic Outcomes between Open and Robotic Assisted Laparoscopic Prostatectomy in a Contemporary Population Based Cohort. J Urol 2016;196:76-81.

88. Pilecki MA, McGuire BB, Jain U, et al. National multiinstitutional comparison of 30-day postoperative complication and readmission rates between open retropubic radical prostatectomy and robot-assisted laparoscopic prostatectomy using NSQIP. J Endourol 2014;28:430-6.

89. Woldu SL, Weinberg AC, Bergman A, et al. Pain and analgesic use after robot-assisted radical prostatectomy. J Endourol 2014;28:544-8.

90. Plym A, Chiesa F, Voss M, et al. Work Disability After Robot-assisted or Open Radical Prostatectomy: A Nationwide, Population-based Study. Eur Urol 2016;70:64-71.

91. Webster TM, Herrell SD, Chang SS, et al. Robotic assisted laparoscopic radical prostatectomy versus retropubic radical prostatectomy: a prospective assessment of postoperative pain. J Urol 2005;174:912-4; discussion 4.

92. von Mechow S, Graefen M, Haese A, et al. Return to work following robot-assisted laparoscopic and open retropubic radical prostatectomy: A single-center cohort study to compare duration of sick leave. Urol Oncol 2018;36:309.e1-6.

93. Nguyen PL, Gu X, Lipsitz SR, et al. Cost implications of the rapid adoption of newer technologies for treating prostate cancer. J Clin Oncol 2011;29:1517-24.

94. Kim SP, Shah ND, Karnes RJ, et al. Hospitalization costs for radical prostatectomy attributable to robotic surgery.
Eur Urol 2013;64:11-6.

95. Chandrasekar T, Tilki D. Robotic-assisted vs. open radical prostatectomy: an update to the never-ending debate. Transl Androl Urol 2018;7:S120-3.

96. Patel SV, Yu D, Elsolh B, et al. Assessment of Conflicts of Interest in Robotic Surgical Studies: Validating Author's Declarations With the Open Payments Database. Ann Surg 2018;268:86-92.

97. Criss CN, MacEachern MP, Matusko N, et al. The Impact of Corporate Payments on Robotic Surgery Research: A Systematic Review. Ann Surg 2019;269:389-96.

98. Ramirez D, Maurice MJ, Kaouk JH. Robotic perineal radical prostatectomy and pelvic lymph node dissection using a purpose-built single-port robotic platform. BJU Int 2016;118:829-33.

99. Dalela D, Jeong W, Prasad MA, et al. A Pragmatic Randomized Controlled Trial Examining the Impact of the Retzius-sparing Approach on Early Urinary Continence Recovery After Robot-assisted Radical Prostatectomy. Eur Urol 2017;72:677-85.

100. Sood A, Abdollah F, Menon M. Retzius-sparing robotassisted radical prostatectomy. BJU Int 2019;123:7-8.

101.Kaouk J, Bertolo R, Eltemamy M, et al. Single-Port Robot-Assisted Radical Prostatectomy: First Clinical Experience Using The SP Surgical System. Urology 2019;124:309.

102. Azhar RA, Bochner B, Catto J, et al. Enhanced Recovery after Urological Surgery: A Contemporary Systematic Review of Outcomes, Key Elements, and Research Needs. Eur Urol 2016;70:176-87.

103.Abou-Haidar H, Abourbih S, Braganza D, et al. Enhanced recovery pathway for radical prostatectomy: Implementation and evaluation in a universal healthcare system. Can Urol Assoc J 2014;8:418-23.

104. Trinh QD, Bjartell A, Freedland SJ, et al. A systematic review of the volume-outcome relationship for radical prostatectomy. Eur Urol 2013;64:786-98.

105. Wilt TJ, Shamliyan TA, Taylor BC, et al. Association between hospital and surgeon radical prostatectomy volume and patient outcomes: a systematic review. J Urol 2008;180:820-8; discussion 8-9.

Cite this article as: Pessoa RR, Maroni P, Kukreja J, Kim SP. Comparative effectiveness of robotic and open radical prostatectomy. Transl Androl Urol 2021;10(5):2158-2170. doi: 10.21037/tau.2019.12.01 